\title{
Channel length-dependent characterisations of organic thin-film transistors with solution processable gadolinium phthalocyanine derivatives
}

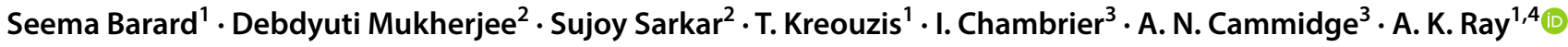

Received: 10 October 2019 / Accepted: 30 October 2019 / Published online: 21 November 2019

(c) The Author(s) 2019

\begin{abstract}
Spin-coated 52-nm-thick films of newly synthesised gadolinium liquid crystalline bisphthalocyanine sandwich $\left(\mathrm{GdPc}_{2}\right)$ complexes with octyl chains non-peripheral positions have been successfully employed as active layers for bottom-gate organic field effect transistors having both short $(5 \mu \mathrm{m})$ and long $(20 \mu \mathrm{m})$ channels. The scaling down of the channel length $(L)$ decreases the field effect mobility due to the increase in the contact resistance between the gold electrodes and the $\mathrm{GdPc}_{2}$ semiconducting layer. Values of on-off ratio and sub-threshold voltage swing are higher nearly one order of magnitude for $L=5 \mu \mathrm{m}$ than those for $L=20 \mu \mathrm{m}$.
\end{abstract}

\section{Introduction}

Lanthanide bisphthalocyanine sandwich compounds $\left(\mathrm{LnPc}_{2}\right)$ in which the large conjugated $\pi$ systems are held in close proximity by rare-earth ions, are characterised by their free radical character, facilitating electron transfer from one molecule to another in the solid state. These thermally stable, environmentally friendly and non-toxic compounds exhibit high intrinsic conductivities, small activation energy and large electronic affinity compared to those of monophthalocyanines [1] and have attracted great attention because of their potential applications in molecular electronics [2], organic field effect transistors (OTFTs) [3], molecular optronics [4], molecular iono-electronics [5] and chemical sensors [6]. Electrochemical and spectroelectro-chemical responses of the complexes to the $\pi-\pi$ interaction are found

A. K. Ray

asim.ray@brunel.ac.uk

1 Centre of Materials Research, Queen Mary University of London, Mile End Road, London E1 4NS, UK

2 Institute of Chemistry, The Hebrew University of Jerusalem, Jerusalem, Israel

3 School of Chemistry, University of East Anglia, Norwich NR4 7TJ, UK

4 Present Address: Department of Electronic and Computer Engineering, Brunel University London, Uxbridge UB8 3PH, UK to be influenced by central metal ions and substituents on rings. Redox peaks shifted towards the negative potentials as a function of the decreasing metal ion size [7]. Studies on chemichromic interactions between lutetium bis-octaalkylsubstituted phthalocyanines and biological cofactors namely nicotinamide adenine dinucleotide and L-ascorbic acid of concentrations ranging from $3.5 \mathrm{mM}$ down to $0.03 \mathrm{mM}$ can be adapted for developing practical devices in plasma, serum, red cells, urine and other accessible tissues for biochemical and functional status [8]. These complexes may potentially be used as emitters in different types of organic light-emitting diodes, depending upon their emission wavelengths. The emission in near-infrared region can be used for night-vision devices [9].

$\mathrm{LnPc}_{2}$ compounds are found to be intrinsic semiconductors, with the field effect hole mobility in the order of $10^{-2} \mathrm{~cm}^{2} \mathrm{~V}^{-1} \mathrm{~s}^{-1}$ at the interface between the lutetium bisphthalocyanine $\left(\mathrm{LuPc}_{2}\right)$ active layer and gold electrode. This value is lower than in the bulk [10]. The high energy level of highest occupied molecular orbital and low energy level of lowest unoccupied molecular orbital in the sandwich double-decker molecules are induced by the intrinsic delocalised hole leading to small ionisation potential and large electronic affinity [11]. The introduction of the $\mathrm{LuPc}_{2}$ buffer layer between the active copper monophthalocyanine layer and gold electrodes produces twofold increase in the field effect hole mobility coupled with the fall in threshold voltage by factor of 2 and high on off ratio in the order of $10^{4}$. The Fermi level and interface dipolar between $\mathrm{LuPc}_{2}$ and 
Au electrode is believed to be responsible for this improved performance [12]. The bisphthalocyanine arrangement coordinated by the $\mathrm{Gd}^{3+}$ template in $\mathrm{GdPc}_{2}$ represents a very stable $\pi$-electronic bonding system. Using thermally deposited Gadolinium bisphthalocyanine $\left(\mathrm{GdPc}_{2}\right)$ active layers, values of $8 \times 10^{-6} \mathrm{~cm}^{2} \mathrm{~V}^{-1} \mathrm{~s}^{-1}$ and $4 \times 10^{-5} \mathrm{~cm}^{2} \mathrm{~V}^{-1} \mathrm{~s}^{-1}$ have been estimated for the field effect mobilities of holes and electrons, respectively, showing ambipolar-type behaviour [13]. However, the accuracy of the extracted values is limited because the methods of extraction are based on gradual channel approximations for the drain current relation in which a linear potential profile across the channel between the gate and the source is assumed to exist. It is important to consider contact and channel properties for the full interpretation of experimental output and transfer characteristics [14]. The drain and source contact resistances are likely to limit the device charge carrier mobility and the switching speed of transistors [15].

Solution processable liquid crystalline phthalocyanines are becoming the more preferred owing to their easier deposition techniques such as spin-coating as well as their ability to respond to thermal annealing for example, to re-arrange the bulk structure, i.e. face-on or homeotropic alignment of the columnar domains in relation to the surface to improve electrical characteristics [16]. The liquid crystalline mesophases of peripherally octakis(octyloxy) gadolinium bisphthalocyanine display a hexaganol columnar and/or rectangular columnar molecular arrangement depending on the molecular structure of sandwiches, These derivatives exhibit the phase transition from crystal to columnar mesophase at $61{ }^{\circ} \mathrm{C}$ while the columnar mesophase to hexagonal packing transition is found to occur the temperature of $93^{\circ} \mathrm{C}$. This suggests the cooperation of the $\pi-\pi$ stacking and the influence of octyloxy side chains on the liquid crystal formation [17]. The transistor parameters of OTFTs using 150-nm-thick spin-coated films of peripherally hexylthio-substituted liquid-crystalline lutetium phthalocyanine as the active layers were found to be sensitive to the molecular orientations depending upon the post-deposition heat treatment of the films. The disordered as-deposited films acquired the hexagonal columnar mesosphere when annealed at $125{ }^{\circ} \mathrm{C}$. The films became isotropic liquid at $242{ }^{\circ} \mathrm{C}$ but the crystalline phase $\mathrm{K}_{3}$ was formed as it was cooled down to room temperature at the rate of $10{ }^{\circ} \mathrm{C} \mathrm{min}^{-1}$. For the channel length of $5 \mathrm{~nm}$, the increase of field effect hole mobility was observed from $7.9 \times 10^{-5} \mathrm{~cm}^{2} \mathrm{~V}^{-1} \mathrm{~s}^{-1}$ to $58 \times 10^{-5} \mathrm{~cm}^{2} \mathrm{~V}^{-1} \mathrm{~s}^{-1}$ as the as-deposited film was annealed at $242^{\circ} \mathrm{C}$ while the threshold voltage decreased by nearly $2 \mathrm{~V}$ [18]. An increase in the field effect hole mobility was observed from $1.5 \times 10^{-3} \mathrm{~cm}^{2} \mathrm{~V}^{-1} \mathrm{~s}^{-1}$ for the as-deposited octylsubstituted lutetium phthalocyanine $\left(\mathrm{R}_{16} \mathrm{LuPc}_{2}\right)$ active layer in the OTFTs to $8.0 \times 10^{-3} \mathrm{~cm}^{2} \mathrm{~V}^{-1} \mathrm{~s}^{-1}$ for the active layer annealed at $70^{\circ} \mathrm{C}$. One order of magnitude increase for the on-off ratio was found for the annealed films over that of the as-deposited films. The threshold voltage of the as-deposited device is halved from $-25 \mathrm{~V}$ to $-12.5 \mathrm{~V}$ for the annealed device while the decrease in the subthreshold voltage swing was observed from $3.8 \mathrm{~V} /$ decade to $1.6 \mathrm{~V} /$ decade for the annealed film [19].

This paper reports the room temperature characteristic parameters of bottom-gate, bottom-contact organic thinfilm transistors (OTFTs) for two channel lengths $L L=5 \mu \mathrm{m}$ and $L=20 \mu \mathrm{m}$ using $52 \mathrm{~nm}$ thick solution processed films of a novel liquid crystalline gadolinium bisphthalocyanine complex $\left(8 \mathrm{GdPc}_{2}\right)$ in Fig. 1, bearing a total of 16 octyl chains $\left(R=\mathrm{C}_{8} \mathrm{H}_{17}\right)$ as substituents on its non-peripheral $1,4,8,11,15,18,22,25$-positions. UV-Vis absorption spectra and surface morphology of for spin-coated films have been studied in relation to the physical analysis of experimental OTFT results.

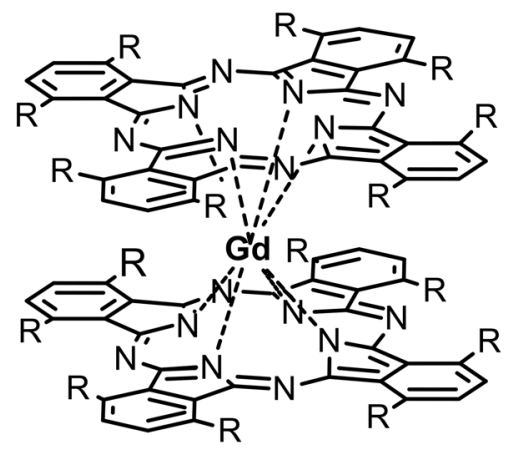

(a)

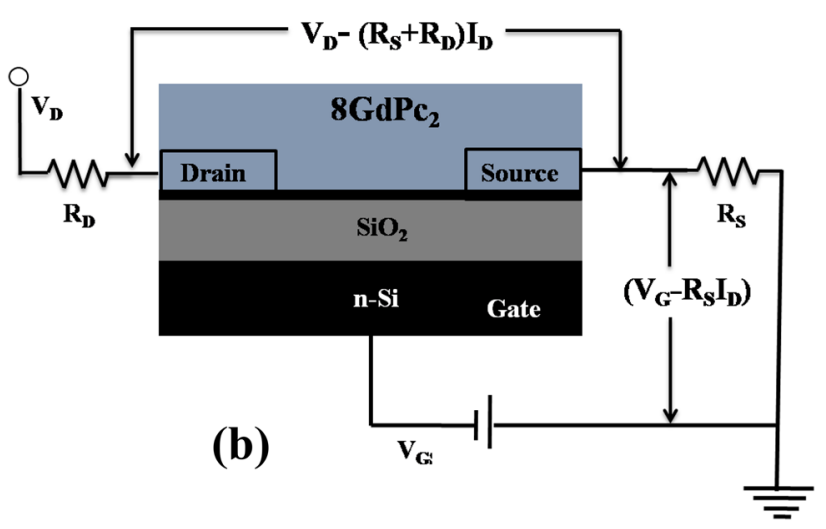

Fig. 1 a Chemical structure of non-peripherally octaoctyl-substituted bis-1,4,8,11,15,18,22,25-octakis(octyl) phthalocyaninato gadolinium $\left(8 \mathrm{GdPc}_{2}\right)$ and $\mathbf{b}$ bottom-gate, bottom-contact OFET structure with channel length $L=5 \mu \mathrm{m}$ and $20 \mu \mathrm{m}$, channel width $W=10 \mathrm{~mm}$ and active film layer $\left(8 \mathrm{GdPc}_{2}\right)$ thickness $\mathrm{d}_{\mathrm{F}}=52 \mathrm{~nm}$ 


\subsection{Experimental details}

Synthetic routes to bis-complexes of tetrapyrrole based macrocycles containing a lanthanide metal ion are well established. The metal-free 1,4,8,11,15,18,22,25-octakis(octyl) phthalocyanine was reacted with gadolinium acetate under reflux in octanol with 1,8-Diazabicyclo[5.4.0]undec-7-ene (DBU) as a promoter to produce gadolinium bisphthalocyanine [20]. Pre-patterned bottom-gate/bottom-contact (OTFTs) with highly doped (resistivity $1-5 \Omega \mathrm{cm}$ ) silicon (110) gate electrode substrates and octadecyltrichlorosilane (OTS)-treated 200-nm-thick $\mathrm{SiO}_{2}$ as thermally grown $(200 \mathrm{~nm})$ as the gate dielectric was used. The gold source/ drain was photolithographically patterned. Prior to the device fabrication, the substrates were cleaned thoroughly in acetone, iso-propanol and finally in deionised water. The gate capacitance $C_{i}$ per unit area of the oxide was found to be $16 \mathrm{nF} \mathrm{cm}^{-2}$. Employing a KW-4A two-stage spin coater (Chemat Technology Inc), the organic semiconductor $\left(8 \mathrm{GdPc}_{2}\right)$ solution in chloroform $(0.5 \mathrm{wt} \%)$ was spincoated at the speed of $500 \mathrm{rpm}$ for $30 \mathrm{~s}$ and subsequently $1500 \mathrm{rpm}$ for $60-90 \mathrm{~s}$ onto the substrate at ambient conditions. Using a DekTak profilometer, the thickness of the $8 \mathrm{GdPc}_{2}$ layer was measured to be $\sim 52 \mathrm{~nm}$. The channel width $W$ remained unchanged at $10 \mathrm{~mm}$ but two different channel lengths $L=5 \mu \mathrm{m}$ and $L=20 \mu \mathrm{m}$, respectively, were investigated for the $8 \mathrm{GdPc}_{2}$ active layers of the same thickness. The transistors were characterised in a probe station at ambient using the Kiethley Semiconducting Parameter Analyser 4200. Further information is available from one of earlier publications [21].

Optical absorption spectra of the spin-coated $8 \mathrm{GdPc}_{2}$ film on ultrasonically cleaned quartz slide were recorded using a Perkin Elmer LAMBDA 650 UV-Visible spectrophotometer with reference to absorption through a similar bare quartz slide. Surface morphology of thin spun film was examined with atomic force microscopy (AFM) utilising a Digital Instruments Dimension 3100 scanning probe microscope, operating in intermittent contact (tapping) mode with a Nanosensors silicon probe with a resonant frequency of approximately $160 \mathrm{kHz}$.

\section{Results and discussions}

The UV-Vis electronic absorption spectrum of the as-deposited $8 \mathrm{GdPc}_{2}$ spun thin film is shown in Fig. 2. This compound shows the crystal-columnar mesophase and columnar mesophase-isotropic liquid transitions at $64.2{ }^{\circ} \mathrm{C}$ and $162{ }^{\circ} \mathrm{C}$, respectively [22] and, therefore, the spectrum of the as-deposited film which exhibits absorptions at $\sim 390,475$, 640 and $730 \mathrm{~nm}$ is characteristic of the crystal $(K)$ structure [20]. The broad band at $\sim 390 \mathrm{~nm}$ is assigned to the Soret band $\left(\pi-\pi^{*}\right)$ and the two broad bands, at $\sim 640$ and $730 \mathrm{~nm}$ are the characteristics Q-band, split into $\mathrm{Q}_{\mathrm{x}}\left[\mathrm{b}_{1 \mathrm{u}}(\pi) \rightarrow\right.$ $\left.\mathrm{e}_{\mathrm{g}}\left(\pi^{*}\right)\right]$ and $\mathrm{Q}_{\mathrm{y}}\left[\mathrm{a}_{2 \mathrm{u}}(\pi) \rightarrow \mathrm{e}_{\mathrm{g}}\left(\pi^{*}\right)\right]$, respectively. These bands are due to long range face-to-face stacking arrangements of the monomers. A shoulder at $475 \mathrm{~nm}$ is attributed to the presence of radical $\mathrm{Pc}^{-}$species in typical sandwich-type bisphthalocyanine compounds and the corresponding electronic transition is $\left[2 \mathrm{e}_{1 \mathrm{~g}}(\pi) \rightarrow 2 \mathrm{a}_{2 \mathrm{u}}(\pi)\right.$ ] [23]. These optical transitions are schematically described in Fig. $2 b$ in terms of energy level corresponding to singly degenerate orbitals and doubly degenerate orbitals. According to the extended Hückel molecular orbital model, doubly degenerate lowest unoccupied molecular orbital (LUMO) is believed to have centred on the pyrrole and isoindole nitrogen. The interactions between the macrocyclic rings split the $\pi$ highest occupied molecular orbital (HOMO) levels in the lanthanide sandwich complexes [24]. The relative energy distance between the bonding HOMO and LUMO levels is estimated to be $1.73 \mathrm{eV}$. Similar absorption pattern was observed for a mixture of oxidised $\left[\mathrm{Gd}^{\mathrm{III}}\left(\mathrm{Pc}^{2-}\right) \mathrm{Pc}^{--}\right]$and neutral species $\left[\mathrm{Pc}^{2-}\left(\mathrm{Gd}^{\mathrm{III}}\right) \mathrm{PcH}\right][25]$.

Figure 3 displays non-crystalline morphology of the asdeposited film. The root mean square value of surface roughness is estimated to be $1.04 \mathrm{~nm}$, indicating average deviation from the mean line. The white spots indicate aggregation
Fig. 2 a UV-Vis spectra b optical transitions of the asdeposited $8 \mathrm{GdPc}_{2}$ thin film (a denotes the orbitals having $\mathrm{C}_{\mathrm{n}}$ axis; $b$ denotes the orbitals that do not have $\mathrm{C}_{\mathrm{n}}$ axis, Subscript 1 denotes the orbitals having $\sigma_{\mathrm{v}}$ plane; subscript 2 denotes the orbitals that do not have $\sigma_{\mathrm{v}}$ plane, e denotes doubly degenerate orbitals, whereas $\mathrm{a}, \mathrm{b}$ denote singly degenerate orbitals.)
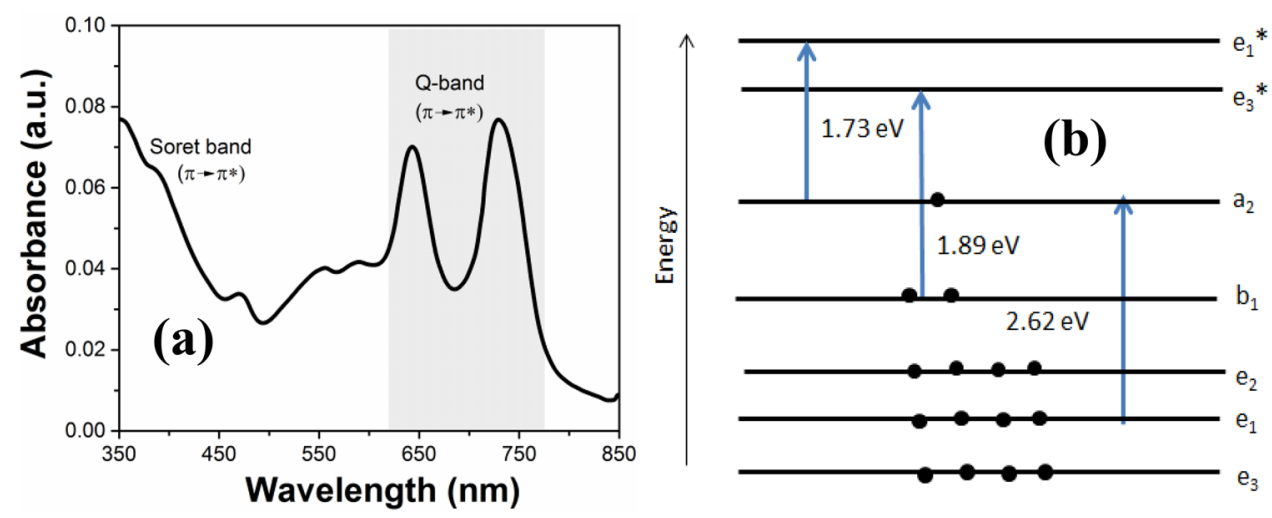


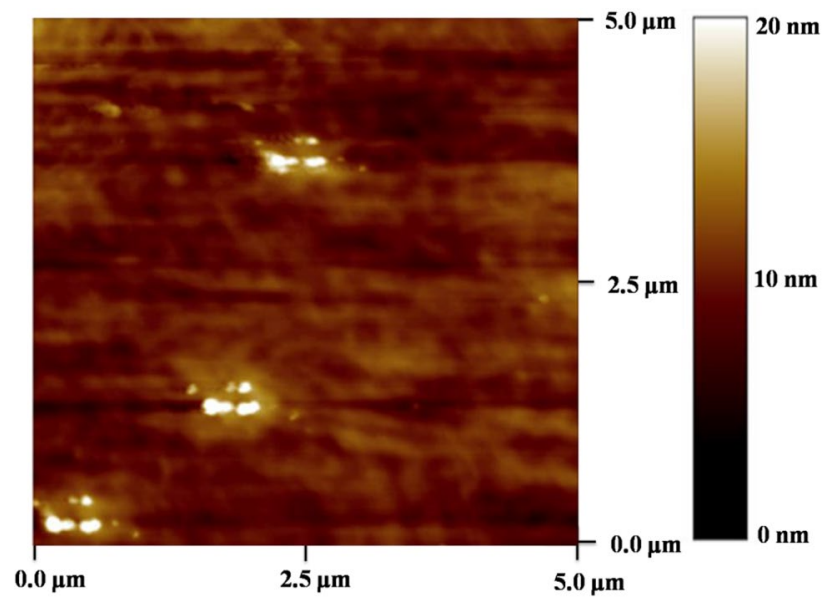

Fig. 3 AFM images of spin cast $8 \mathrm{GdPc}_{2}$ film

materials on the surface, producing a relatively high value of 3.09 for kurtosis (peak sharpness). The values of the maximum height of variation and skewness (symmetry) are found to be $11.08 \mathrm{~nm}$ and -0.08 , respectively. Negative skew is a criterion for a good adhesion to the substrate surface [26].

Output characteristics in Fig. 4 of the $8 \mathrm{GdPc}_{2}$ OTFTs shows the increase of drain-source conductivity with $\mathrm{V}_{\mathrm{G}}$ indicating the field effect operation in a p-type accumulation mode for both channel lengths of $5 \mu \mathrm{m}$ and $20 \mu \mathrm{m}$ [27]. At the negative gate bias, the voltage drop over the interface between the gate dielectric and the active semiconductor layer causes the band bending in the $8 \mathrm{GdPc}_{2}$ layers and as a result an accumulation layer is formed from the additional supply of positive charges from the drain and source contacts [28]. $\mathrm{I}_{\mathrm{D}}$ which is found to be larger by one order of magnitude for shorter channel length than longer length increases linearly within the low $\mathrm{V}_{\mathrm{D}}$ regime, implying a uniform charge density in the channel. Also, the saturation regime seems to be absent from the output characteristics in $4 \mathrm{a}$ for the channel length of $5 \mu \mathrm{m}$. This behaviour is similar to the output characteristics of spincoated 100-nm-thick poly-3-hexylthiophene (P3HT) active layer in a similar configured bottom-contact OTFTs. As the channel length decreases, both Poole-Frenkel mobility and space-charge-limited conduction (SCLC) become dominant, leading to loss of saturation [29].

The charges, however, became depleted over the entire thickness of the active layers at the positive gate voltage $V_{G} \leq 5 \mathrm{~V}$, producing significantly reduced $\mathrm{I}_{\mathrm{D}}$. The value of $5.5 \times 10^{22} \mathrm{~m}^{-3}$ for the maximum charge carrier density $\mathrm{N}_{\mathrm{A}}$ may be estimated from the knowledge depletion width $w_{\text {dep }}$ and the effective capacitance per unit area $C_{\mathrm{i}}$ of the gate in the form [30]:
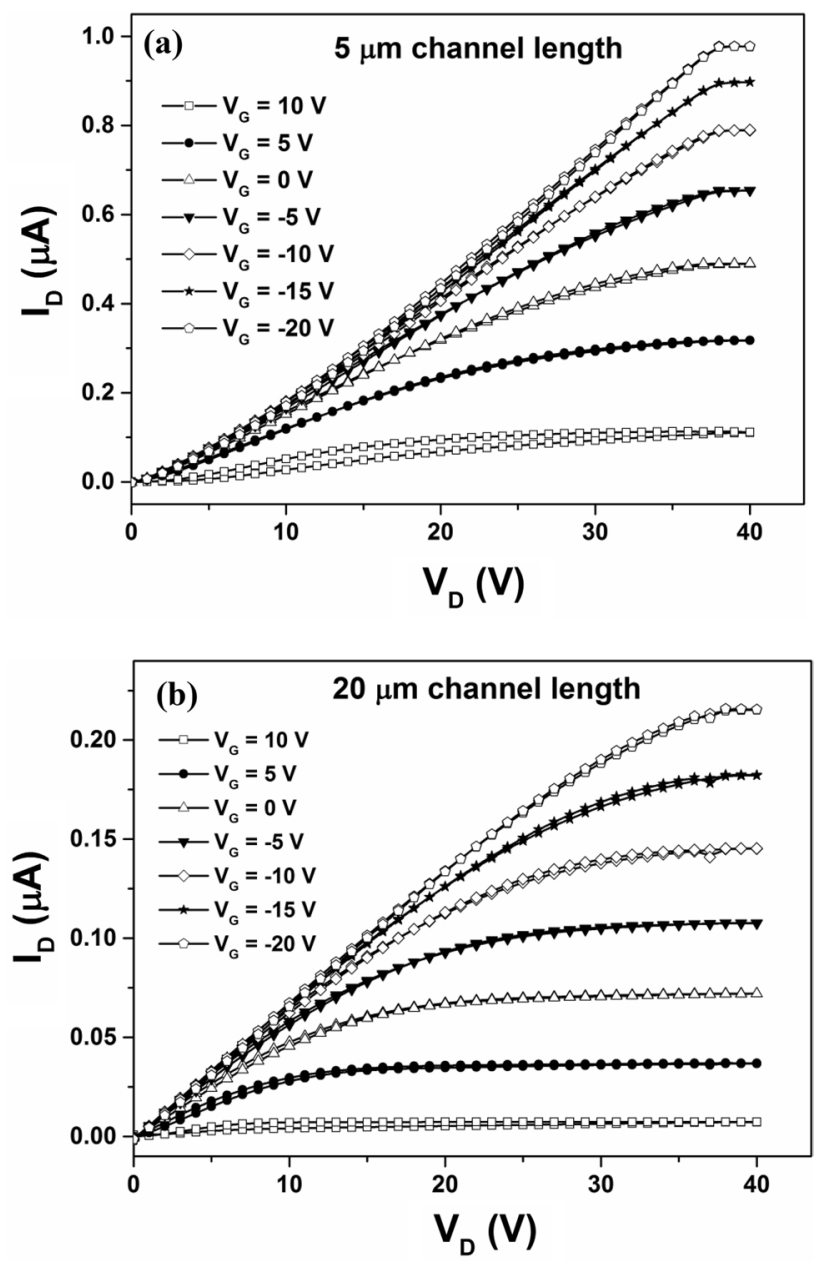

Fig. 4 Output characteristics for an OTFT with the $8 \mathrm{GdPc}_{2}$ films, having a $L=5 \mu \mathrm{m}$ (triangle) and $\mathbf{b} L=20 \mu \mathrm{m}$ (rectangle) in terms of the variation of the drain current $I_{D}$ as a function of the negative drain voltage $\mathrm{V}_{\mathrm{D}}$ for $\mathrm{V}_{\mathrm{G}}$

$w_{\mathrm{dep}}=\frac{\varepsilon_{\mathrm{Gdpc}}}{C_{i}}\left[\left(1+\frac{2 \mathrm{C}_{i}^{2} V_{\mathrm{G}}}{\mathrm{qN}_{\mathrm{A}} \varepsilon_{\mathrm{Gdpc}}}\right)^{1 / 2}-1\right]$

The value of $w_{\text {dep }}=52 \mathrm{~nm}$ was taken since the depletion zone was expected to extend into the entire depth of the $8 \mathrm{GdPc}_{2}$ film. The value of effective capacitance $C_{i}$ per unit area for the OTS-treated $\mathrm{SiO}_{2}$ gate insulator was estimated to be $1 \times 10^{-4} \mathrm{Fm}^{-2}$ using the value of $1 \times 10^{-2} \mathrm{~F} \mathrm{~m}^{-2}$ for the OTS monolayer [21]. The free permittivity $\varepsilon_{0}=8.85 \times 10^{-12}$ $\mathrm{Fm}^{-1}$, the electronic charge $q=1.6 \times 10^{-19} \mathrm{C}$ and the dielectric constant of $8 \mathrm{GdPc}_{2} \varepsilon_{\mathrm{Gdpc}} \approx 3.35$ were used for the calculations [31].

The transfer characteristics at $V_{\mathrm{D}}=-5 \mathrm{~V}$ and $V_{\mathrm{D}}=-40 \mathrm{~V}$ in Fig. 5 show a varied degree of the hysteresis, the magnitude depending upon channel lengths. The 

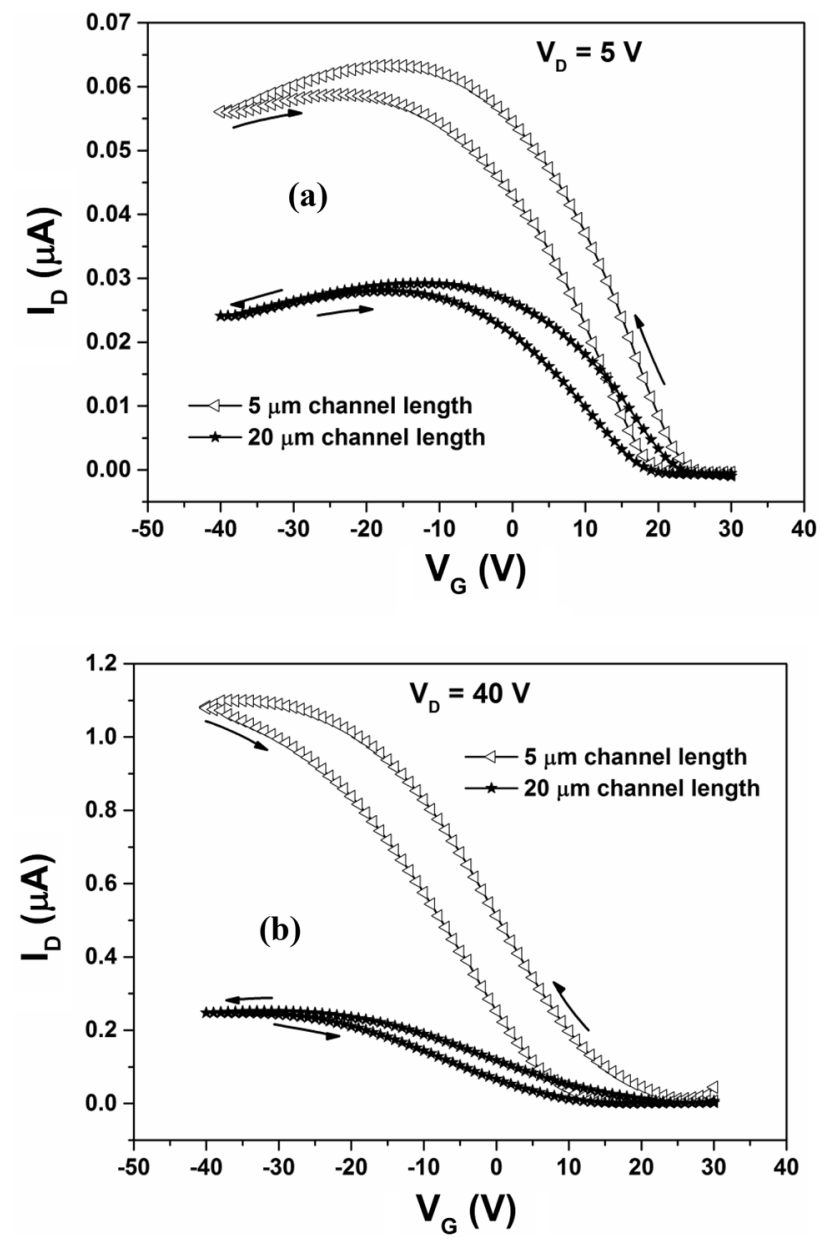

Fig. 5 Transfer characteristics for an OTFT with the $\mathrm{GdPc}_{2}$ films, having $5 \mu \mathrm{m}$ (open triangle) and $20 \mu \mathrm{m}$ (solid star) channel length for a $V_{D}=5 \mathrm{~V}$ and $\mathbf{b V}_{\mathrm{D}}=40 \mathrm{~V}$ corresponding to linear and saturation regions

transfer characteristics obtained for $20 \mu \mathrm{m}$ channel length are, however, nearly free of hysteresis at $V_{\mathrm{G}} \leq-30 \mathrm{~V}$ for both $V_{\mathrm{D}}=-5 \mathrm{~V}$ and $V_{\mathrm{D}}=-40 \mathrm{~V}$. Values of $10.03 \mu \mathrm{W}$ and $1.82 \mu \mathrm{W}$ were obtained by the numerical integration for the area of the hysteresis loops for $L=5 \mu \mathrm{m}$ and $L=20 \mu \mathrm{m}$, respectively. This represents more than 5 fold reduction in energy consumption of the longer channel device for $\mathrm{V}_{\mathrm{D}}=-40 \mathrm{~V}$. Reduction in energy consumption is also observed for $\mathrm{V}_{\mathrm{D}}=-5 \mathrm{~V}$ with the area values of $0.488 \mu \mathrm{W}$ and $0.199 \mu W$ for the channel lengths $L=5 \mu \mathrm{m}$ and $L=20 \mu \mathrm{m}$, respectively. The drain current is found to be higher in the off-to-on than the on-to-off sweep. During off-to-on sweep, empty traps in the $8 \mathrm{GdPc}_{2}$ film near the $\mathrm{SiO}_{2}$ interface became filled by a portion of holes induced by the negative gate voltage $\mathrm{V}_{\mathrm{G}}$. These holes remained largely trapped during the on-to-off sweep because the rate of release of trapped holes is slower than that of the sweep of $\mathrm{V}_{\mathrm{G}}$ [32]. Comparable hysteresis behaviour was observed for a 150 -nm-thick 2,9(10),16(17),23(24)-(13,17-dioxanonacosane-15-oxy) phthalocyaninatozinc(II) compound layer in an OTFT structure similar to one used in the present investigation [33].

The current modulation (on/off current ratio) was found to be $10^{3}$ and $2 \times 10^{2}$ from the transfer characteristic in Fig. 5 of $\mathrm{I}_{\mathrm{D}}$ versus $V_{\mathrm{G}}$ for drain voltage $V_{\mathrm{DS}}$ of $-40 \mathrm{~V}$ for channel lengths $L=5 \mu \mathrm{m}$ and $L=20 \mu \mathrm{m}$, respectively. The sub-threshold voltage swing $\mathrm{S}$ defined as the voltage $V_{\mathrm{G}}$ required to increase the drain-to-source current $I_{\mathrm{D}}$ by a factor of 10 was calculated using the following equation [34]:

$S=\frac{\mathrm{d} V_{\mathrm{G}}}{\mathrm{d}\left(\log _{10} I_{\mathrm{D}}\right)}$

Values of $\mathrm{S}=9.7 \mathrm{Vdecade}^{-1}$ and $S=6.8 \mathrm{Vdecade}^{-1}$ were determined for channel lengths $L=5 \mu \mathrm{m}$ and $L=20 \mu \mathrm{m}$, respectively. The decrease of $S$ with increasing channel length is consistent with the reported observation for thermally deposited copper phthalocyanine OTFTs with varying channel lengths [35].

The transistor parameters are believed to be dependent upon the $\mathrm{SiO}_{2} / 8 \mathrm{GdPc}_{2}$ interface. Values of $1.02 \times 10^{15} \mathrm{~m}^{-2}$ and $7.12 \times 10^{14} \mathrm{~m}^{-2}$ are obtained for the density $N_{\mathrm{T}}$ of traps at the interface between the $8 \mathrm{GdPc}_{2}$ layer and the gate $\mathrm{SiO}_{2}$ dielectrics using the equation [36]:

$N_{\mathrm{t}}=\left[\frac{\mathrm{S} \log (e)}{(\mathrm{kT} / q)}-1\right] \frac{C_{i}}{q}$

Nearly one order magnitude increase in $N_{\mathrm{T}}$ for the shorter channel may be attributed to the increased accumulation region of holes especially in the source region [37].

The charge carriers induced by the gate voltage in the channel become trapped in the polycrystalline film as observed in the AFM pictures for the present $8 \mathrm{GdPc}_{2}$ film. The active phthalocyanine layer is believed to have formed Schottky-type contacts with both source and drain electrodes. Therefore, the carrier movement in the bottom-contact OTFT contact is mainly influenced by the contact resistances $R_{S}$ and $R_{\mathrm{D}}$ at the source and the drain contacts, respectively, as shown in Fig. 1b. The mobility of the carriers is therefore dependent upon the gate voltage $\mathrm{V}_{\mathrm{G}}$ in a power law form in the form [38]

$\mu=\mu_{0}\left[V_{\mathrm{G}}-\left(R_{\mathrm{S}}+R_{\mathrm{D}}\right) I_{\mathrm{D}}-V_{\mathrm{T}}\right]^{\gamma}$

according to the transit time between the source and drain electrodes, where $\mu_{0}$ is a fitting parameter defined as the mobility for $\left[V_{\mathrm{G}}-V_{\mathrm{T}}\right]=1$. The drain current $I_{\mathrm{D}}$ is written in terms of the field independent mobility $\mu_{0}$ and threshold voltage $V_{\mathrm{T}}$ in the form [39]:

$I_{D(\operatorname{lin})}=\left(\frac{\mu_{0} C_{i} W}{L}\right)\left(\frac{V_{\mathrm{D}}\left(V_{\mathrm{G}}-V_{\mathrm{T}}\right)^{(\gamma+1)}}{1+\left(R_{S}+R_{\mathrm{D}}\right)\left(V_{\mathrm{G}}-V_{\mathrm{T}}\right)^{(\gamma+1)}}\right)$ 
for linear region

$I_{D(\mathrm{sat})}=\left(\frac{\mu_{0} C_{i} W}{(\gamma+2) L}\right)\left(V_{\mathrm{G}}-R_{S} I_{D(s a t)}-V_{\mathrm{T}}\right)^{(\gamma+2)}$

for saturation region

It is assumed in Eq. (6) that the voltage drop across $R_{\mathrm{D}}$ in the saturation regime is not large enough for significant control of the drain-source current $I_{D(s a t)}$. Values of parameters $\mu_{0}, \gamma$, and $V_{\mathrm{T}}$ have been estimated from the non-linear regression of experimental data to fit Eqs. (5) and (6). Sqcurvefit in MATLAB is employed for this purpose subject to the minimisation of the sum of square fitting errors [40].

The exponent $\gamma=2\left(\frac{T_{C}}{T}-1\right)$ is associated with the isokinetic characteristic temperature $T_{C}$ for the width of the Gaussian or slope of the exponential distribution of traps. For $T_{C}=T$ where the operating temperature $T=300 \mathrm{~K}$, Eqs. (5) and (6) indicate that the characteristics become similar to ones used for the transistors with a single crystal material as an active layer [41]. As evident from the AFM images, the films of both channel lengths are expected to contain high density of traps with isokinetic characteristic Meyer-Neldel energies $\mathrm{E}_{\mathrm{MN}}\left(=\mathrm{kT}_{\mathrm{C}}\right)$ distributed between 29.27 and.27.72 meV of the exponential tail states. For the ratio of $\frac{\mathrm{E}_{\mathrm{MN}}}{\mathrm{kT}} \neq 1$, it can be suggested that trapped charges do not contribute to the drain-to-source current and therefore the mobility $\mu_{\text {sat }}$ becomes dependent upon the ratio of trapped-to-free carriers controlled by the gate bias.

The decrease in values of $V_{\mathrm{T}}$ from $28.9 \mathrm{~V}$ for $L=5 \mu \mathrm{m}$ to $27.6 \mathrm{~V}$ for $L=20 \mu \mathrm{m}$. may be explained in terms of drain induced barrier lowering effect [42]. These values are believed to be related to the bulk trap limited charge transport in the organic layer and the density $N_{B}$ of these traps is related to $V_{\mathrm{T}}$ in the form [43]:

$N_{B}=\frac{V_{\mathrm{T}}^{2} C_{i}^{2}}{2 \varepsilon_{\mathrm{Gdpc}} \varepsilon_{0} \mathrm{kT}}$

Values of $N_{B}=3.83 \times 10^{19} \mathrm{~cm}^{-3}$ and $N_{B}=3.49 \times 10^{19} \mathrm{~cm}^{-3}$ are found for $8 \mathrm{GdPc}_{2}$ films in the OTFTs with $L=5 \mu \mathrm{m}$ and $L=20 \mu \mathrm{m}$ taking the free permittivity $\varepsilon_{0}=8.85 \times 10^{-12} \mathrm{Fm}^{-1}$. These values are the same order of magnitude.

Figure 6 displays the variation of saturated mobility $\left(\mu_{\text {sat }}\right)$ as a function of gate voltage $V_{\mathrm{G}}$ for $8 \mathrm{GdPc}_{2}$ transistors corresponding to the saturation region at $V_{\mathrm{D}}=40 \mathrm{~V}$. In general, $\mu_{\text {sat }}$ is found to be smaller for $L=5 \mu \mathrm{m}$ than $L=20 \mu \mathrm{m}$. The dependence of saturated mobility with the channel length is consistent with the results that have been observed for the top-gate OTFT with P3HT organic semiconductor. As the channel length was decreased, mobility was also decreased revealing pronounced contact resistance of short channel TFT. [44]. This effect is believed to

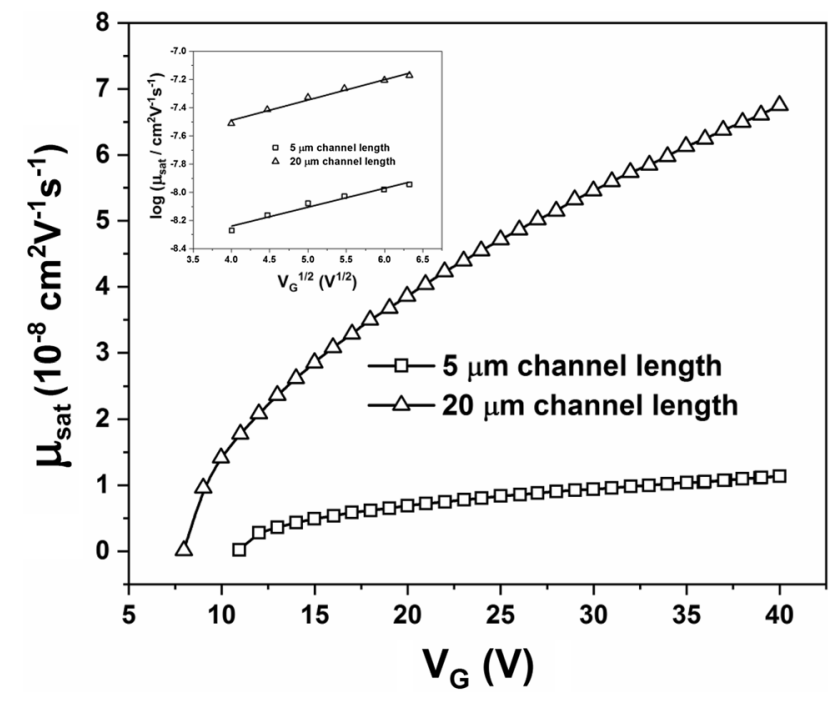

Fig. 6 Saturated mobility $\left(\mu_{\text {sat }}\right)$ as a function of gate voltage $V_{\mathrm{G}}$ for $8 \mathrm{GdPc}_{2}$ transistors corresponding to $L=5 \mu \mathrm{m}$ (rectangle) and $L=20 \mu \mathrm{m}$ (triangle). Inset represents the plot of logarithm of $\mu_{\text {sat }}$ as a function of square root of gate voltage $\sqrt{V_{\mathrm{G}}}$ for $L=5 \mu \mathrm{m}$ (open rectangle) and $L=20 \mu \mathrm{m}$ (open up triangle)

be due to increasing influence of contact resistance. The linear dependence of $\mu_{\text {sat }}$ against $\sqrt{V_{\mathrm{G}}}$ on logarithm-linear scales in the inset of Fig. 6 is believed to imply that the Poole Frankel charge transport mechanism is responsible for this behaviour of type $\mu_{\mathrm{sat}} \infty \exp \left(\sqrt{\beta_{P F} V_{\mathrm{G}}}\right.$. Values of $0.134 \mathrm{~cm}^{2} / \mathrm{V}^{3 / 2}$ s and $0.145 \mathrm{~cm}^{2} / \mathrm{V}^{3 / 2}$ s for the field-lowering coefficient $\beta_{P F}$ are found from the slopes for channel length of $5 \mu \mathrm{m}$ and $20 \mu \mathrm{m}$, respectively. These positive values of $\beta_{P F}$ imply that the positional order is small in comparison with the width of the Gaussian density of energy states [45].

As shown in Fig. 1b, the source and drain contact resistances $R_{S}$ and $R_{\mathrm{D}}$, respectively, may be accounted for in expressions that relate the effective gate-source $V_{\mathrm{G}}-R_{S} I_{\mathrm{D}}$ and drain-source voltage $V_{\mathrm{D}}-\left(R_{S}+R_{\mathrm{D}}\right) I_{\mathrm{D}}$ to their externally applied voltages through the potential drop across the parasitic resistances. Therefore, for small $\mathrm{V}_{\mathrm{D}}$, $R_{\mathrm{SD}}=\left(R_{S}+R_{\mathrm{D}}\right)$ can be written in the form [46]:

$R_{\mathrm{SD}}=\frac{V_{\mathrm{D}}}{I_{\mathrm{D}}}-\left(\frac{L}{\mu_{0} C_{i} W\left(V_{\mathrm{G}}-V_{\mathrm{T}}\right)^{(\gamma+1)}}\right)$

Where $\frac{V_{\mathrm{D}}}{I_{\mathrm{D}}}$ represents the measured resistance of the device in the ON state.

The dependence of $R_{\mathrm{SD}}$ of $8 \mathrm{GdPc} 2$ transistors on $V_{\mathrm{G}}$ for $V_{\mathrm{D}}=5 \mathrm{~V}$ is depicted in Fig. 7 on the log-linear scale, showing that values of $R_{\mathrm{SD}}$ for $L=20 \mu \mathrm{m}$ are smaller than those for $L=5 \mu \mathrm{m}$. This observation is consistent with earlier the behaviour of $\mu_{\text {sat }}$ in relation to $V_{\mathrm{G}}$. The 


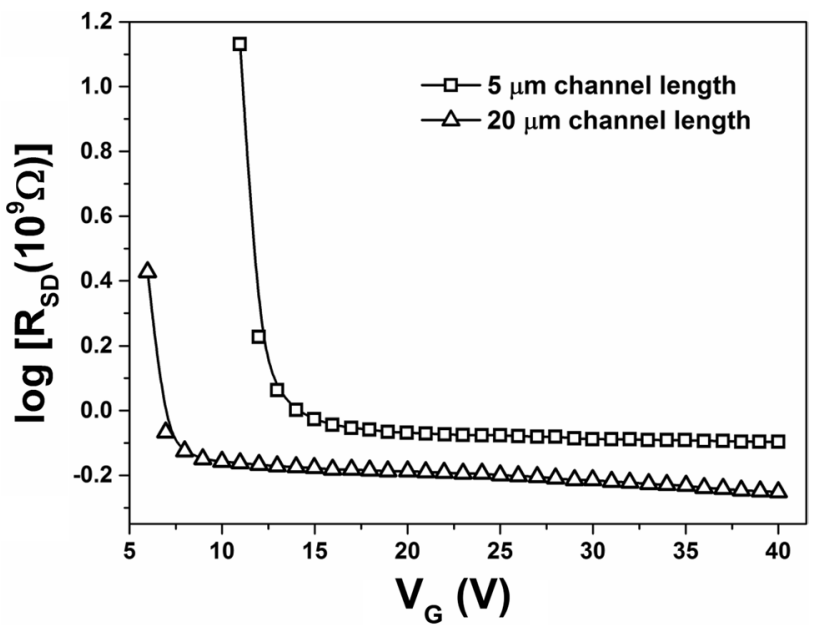

Fig. 7 Plot of $\mathrm{R}_{\mathrm{SD}}$ as a function of gate voltage $V_{\mathrm{G}}$ for $8 \mathrm{GdPc}_{2}$ transistors corresponding to $L=5 \mu \mathrm{m}$ (open rectangle) and $L=20 \mu \mathrm{m}$ (open triangle)

observed decrease in mobility with the decrease in channel length is believed to be due to increasing influence of contact resistance. This agrees with the observation from the compact model for long and short channel lengths of the OTFTs [47]. However, both curves $R_{\mathrm{SD}}\left(V_{\mathrm{G}}\right)$ show similar pattern of behaviour, the initial decrease being sharper corresponding to low values of $V_{\mathrm{G}}$.

The effect of grain boundaries of the active layer on the OTFET characteristics was analysed from the Levinson plots in Fig. 8a of $\ln \left(\frac{I_{\mathrm{D}}}{V_{\mathrm{G}}}\right)$ as $\frac{1}{V_{\mathrm{G}}}$ for $V_{\mathrm{D}}=-5 \mathrm{~V}$. The linear graphs show the dependence of $\mathrm{I}_{\mathrm{DS}}$ on the density $N_{\mathrm{G}}$ of traps at the grain boundaries of the phthalocyanine layer in the form [48]

$$
\begin{aligned}
I_{\mathrm{D}}= & \mu_{\mathrm{GB} 0}\left(V_{\mathrm{D}}-R_{\mathrm{SD}} I_{\mathrm{D}}\right) \frac{W}{L} C_{i}\left(V_{\mathrm{G}}-R_{S} I_{\mathrm{D}}\right) \\
& \exp \left(-\frac{q^{3} N_{\mathrm{G}}^{2} t}{8 \varepsilon_{0} \varepsilon_{\mathrm{pc}} \mathrm{kTC}_{i}\left(V_{\mathrm{G}}-R_{S} I_{\mathrm{D}}\right)}\right)
\end{aligned}
$$

where $\mu_{\mathrm{GB} 0}$ which is the trap free mobility usually depends on the grain size and the carrier concentration, but only slightly on measurement temperature. It is to be noted that the Levinson plots in the present case are not strictly straight line. This may indicate that the grain boundaries may act as traps rather than barriers. Values of $N_{\mathrm{G}}$ and $\mu_{\mathrm{GB} 0}$ were determined from the slope and the extrapolation for $\frac{1}{V_{\mathrm{G}}} \rightarrow 0$. The Boltzmann constant $\mathrm{k}=8.62 \times 10^{-5} \mathrm{eVK}^{-1}$, and temperature $T=300 \mathrm{~K}$ were used for the calculations of $N_{\mathrm{G}}$ from Eq. (9). Figure $8 \mathrm{~b}$ shows that the grain boundary barrier $E_{B}=\frac{q^{3} N_{\mathrm{G}}^{2} t}{8 \varepsilon_{0} \varepsilon_{8 \mathrm{Gdpc}} \mathrm{C}_{i} V_{\mathrm{G}}}$ decreases while the grain boundary mobility $\mu_{\mathrm{GB}}$ increases with $V_{\mathrm{G}}$. $E_{B}$ is smaller for $L=5 \mu \mathrm{m}$ than
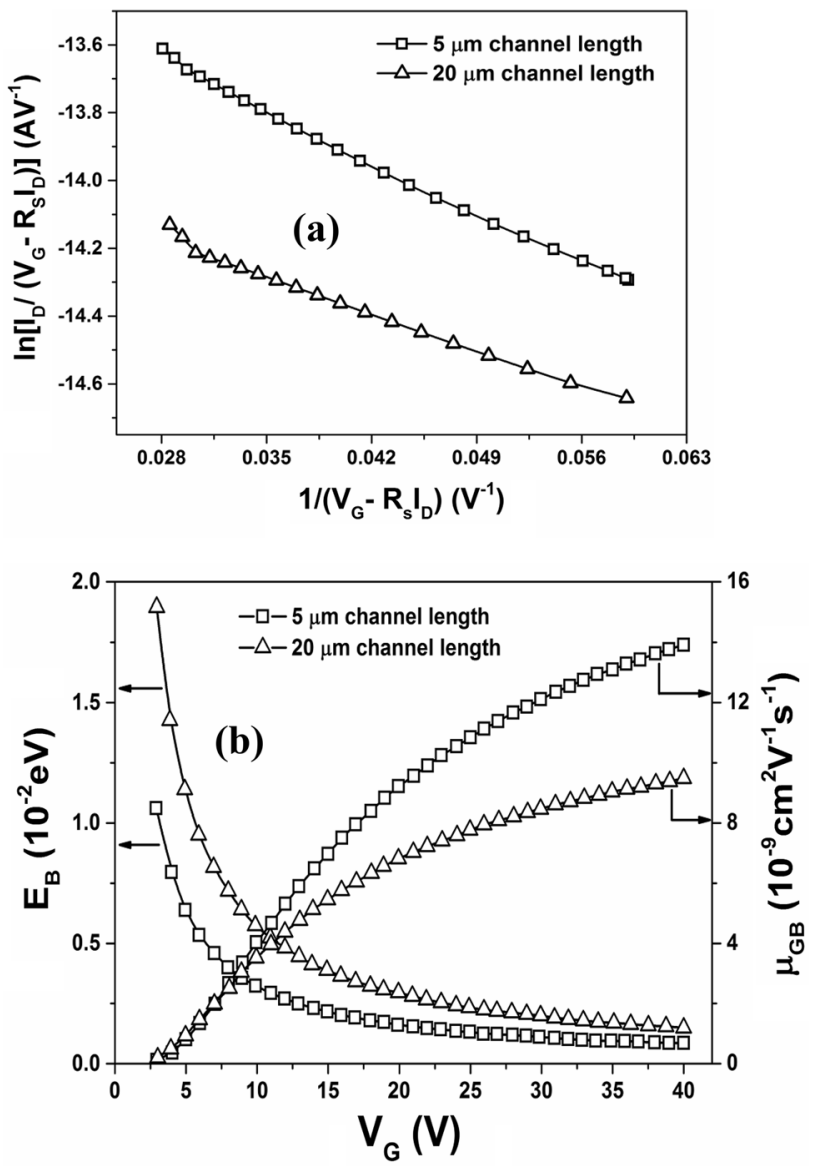

Fig. 8 a Levinson plot for $\mathrm{V}_{\mathrm{D}}=-5 \mathrm{~V}$ for $8 \mathrm{GdPc}_{2}$ films and b Interfacial barrier and the grain boundary mobility corresponding to $L=5 \mu \mathrm{m}$ (rectangle) and $L=20 \mu \mathrm{m}$ (triangle)

those for $L=20 \mu \mathrm{m}$. However, it is found for both channels to undergo sharp decreases at low voltage $V_{G} \sim V_{\mathrm{T}}$ and then the reduction tends to be steady. The density $\mathrm{N}_{\mathrm{g}}$ is believed to be attributed to the parasitic resistance of the device.

Table 1 Summary of transistors parameters

\begin{tabular}{llll}
\hline Active thin film & \multicolumn{2}{l}{$8 \mathrm{GdPc}_{2}$} & $\mathrm{R}_{16} \mathrm{LuPc}_{2}$ \\
\cline { 2 - 4 } Transistor parameter & \multicolumn{2}{l}{ Channel length $L(\mu \mathrm{m})$} \\
\cline { 2 - 4 } & 5 & 20 & 10 \\
\hline$V_{\mathrm{T}}(\mathrm{V})$ & 28.9 & 27.6 & 25 \\
$I_{\text {on }} / I_{\text {off }}$ & $10^{3}$ & $2 \times 10^{2}$ & $10^{3}$ \\
$S(\mathrm{~V} \mathrm{decade}$ & -1 & 3.8 \\
$N_{\mathrm{T}}\left(\times 10^{14} \mathrm{~m}^{-2}\right)$ & 9.7 & 6.8 & 28.1 \\
$N_{B} \times 10^{19} \mathrm{~cm}^{-3}$ & 10.2 & 7.1 & 1.2 \\
$\mu_{0}\left(\times 10^{-5} \mathrm{~cm}^{2} / \mathrm{vs}\right)$ & 3.83 & 3.49 & \\
$\gamma$ & 7.47 & 1.96 & \\
$T_{C}(\mathrm{~K})$ & 0.26 & 0.15 & \\
\hline
\end{tabular}




\section{Concluding remarks}

Values of transistor parameters are summarised in Table 1. It is found that the scaling down of the channel length has significant effects on the saturation mobility and the contact resistance. When the vertical electric field due to the gate voltage $V_{\mathrm{G}}$ not large enough compared to the lateral electric field arising from $V_{\mathrm{D}}$, the control of channel by $V_{\mathrm{G}}$ decreases and the OTFTs may not be turned off. Values of principal parameters for an octyl-substituted lutetium phthalocyanine based transistor have been included and results appear to be consistent. Recent applications of plastic electronics are based on those derivatives bearing substituents that confer both solubility in organic spreading solvents and columnar liquid crystal behaviour typically at elevated temperatures.

Acknowledgements The research was financially supported by the UK Technology Strategy Board (Project No. TP/6/EPH/6/S/K2536J).

Open Access This article is distributed under the terms of the Creative Commons Attribution 4.0 International License (http://creativecommons.org/licenses/by/4.0/), which permits unrestricted use, distribution, and reproduction in any medium, provided you give appropriate credit to the original author(s) and the source, provide a link to the Creative Commons license, and indicate if changes were made.

\section{References}

1. M. Bouvet, P. Gaudillat, J.M. Suisse, Lanthanide macrocyclic complexes: from molecules to materials and from materials to devices". J. Porphyr. Phthalocyanines. 17(8-9), 628-635 (2013)

2. C. Kato, R. Machida, R. Maruyama, R. Tsunashima, X.M. Ren, M. Kurmoo, K. Inoue, S. Nishihara, Giant hysteretic single-molecule electric polarisation switching above room temperature. Angew. Chem. Int. Ed. 57(41), 13429-13432 (2018)

3. G. Horowitz, Organic thin film transistors: from theory to real devices. J. Mater. Res. 19(7), 1946-1962 (2004)

4. A.G. Gurek, T. Basova, D. Luneau, C. Lebrun, E. Kol'tsov, A.K. Hassan, V. Ahsen, Synthesis, structure, and spectroscopic and magnetic properties of mesomorphic octakis(hexylthio)-substituted phthalocyanine rare-earth metal sandwich complexes. Inorg. Chem. 45(4), 1667-1676 (2006)

5. K.P. Birin, Y.G. Gorbunova, A.Y. Tsivadze, Efficient scramblingfree synthesis of heteroleptic terbium triple-decker (porphyrinato) (crown-phthalocyaninates). Dalton Trans. 41(32), 9672-9681 (2012)

6. M.L. Aulsebrook, B. Graham, M.R. Grace, K.L. Tuck, Lanthanide complexes for luminescence-based sensing of low molecular weight analytes. Coord. Chem. Rev. 375, 191-220 (2018)

7. E.B. Orman, A. Koca, A.R. Ozkaya, I. Gurol, M. Durmus, V. Ahsen, Electrochemical, spectroelectrochemical and electrochromic properties of lanthanide bis-phthalocyanines. J. Electrochem. Soc. 161(6), H422-H429 (2014)

8. C. Pal, A.N. Cammidge, M.J. Cook, J.L. Sosa-Sanchez, A.K. Sharma, A.K. Ray, In situ chemichromic studies of interactions between a lutetium bis-octaalkyl-substituted phthalocyanine and selected biological cofactors. J. R. Soc. Interface 9(66), 183-189 (2012)
9. L.D. Wang, Z.F. Zhao, C. Wei, H.B. Wei, Z.W. Liu, Z.Q. Bian, C.H. Huang, Review on the electroluminescence study of lanthanide complexes. Adv. Opt. Mater. 7(11), 1801256 (2019)

10. G. Guillaud, M. Alsadoun, M. Maitrot, J. Simon, M. Bouvet, Field-effect transistors based on intrinsic molecular semiconductors. Chem. Phys. Lett. 167(6), 503-506 (1990)

11. Y.X. Zhang, X. Cai, D.D. Qi, Y.Z. Bian, J.Z. Jiang, Charge transfer properties of bis(phthalocyaninato) rare earth (III) complexes: intrinsic ambipolar semiconductor for field effect transistors. J. Phys. Chem. C 112(37), 14579-14588 (2008)

12. J. Wang, H.B. Wang, J. Zhang, X.J. Yan, D.H. Yan, Organic thin-film transistors with improved characteristics using lutetium bisphthalocyanine as a buffer layer. J. Appl. Phys. 97(2), 026106 (2005)

13. I. Kratochvilova, J. Sebera, B. Paruzel, J. Pfleger, P. Toman, E. Maregova, S. Havlova, P. Hubik, M. Buryi, M. Vrnata, R. Slota, M. Zakrzyk, J. Lancok, M. Novotny, Electronic functionality of Gd-bisphthalocyanine: charge carrier concentration, charge mobility, and influence of local magnetic field. Synth. Met. 236, 68-78 (2018)

14. M. Krammer, J.W. Borchert, A. Petritz, E. Karner-Petritz, G. Schider, B. Stadlober, H. Klauk, K. Zojer, Critical evaluation of organic thin-film transistor models. Crystals. 9(2), 85 (2019)

15. M. Marinkovic, D. Belaineh, V. Wagner, D. Knipp, On the origin of contact resistances of organic thin film transistors. Adv. Mater. 24(29), 4005-4009 (2012)

16. E.B. Melo, J. Eccher, P. Apostol, H. Bock, I.H. Bechtold, Characterization of liquid crystalline phthalocyanines for OFET applications. Mol. Cryst. Liquid Cryst. 657(1), 81-88 (2017)

17. Y. Zhang, J.Z. Jiang, X. Sun, Q.B. Xue, Liquid crystal behaviour of $2,3,9,10,16,17,23,24$-octakis(octyloxy)phthalocyanine-containing gadolinium sandwich complexes. Aust. J. Chem. 62(5), 455-463 (2009)

18. N.B. Chaure, T. Basova, A.K. Ray, A.G. Gurek, V. Ahsen, Memory effects in thin film organic transistor characteristics. J. Phys. D 42(12), 125103 (2009)

19. N.B. Chaure, J.L. Sosa-Sanchez, A.N. Cammidge, M.J. Cook, A.K. Ray, Solution processable lutetium phthalocyanine organic field-effect transistors. Org. Electron. 11(3), 434-438 (2010)

20. A.D. Garland, I. Chambrier, A.N. Cammidge, M.J. Cook, Design and synthesis of liquid crystalline phthalocyanines: combinations of substituents that promote the discotic nematic mesophase. Tetrahedron 71, 7310-7314 (2015)

21. N.B. Chaure, A.N. Cammidge, I. Chambrier, M.J. Cook, M.G. Cain, C.E. Murphy, C. Pal, A.K. Ray, High-mobility solutionprocessed copper phthalocyanine-based organic field-effect transistors. Sci. Technol. Adv. Mater. 12(2), 025001 (2011)

22. S. Barard, T. Kreouzis, A.N. Cammidge, M.J. Cook, A.K. Ray, Newly synthesised gadolinium bisphthalocyanine sandwich complex: ambipolar organic semiconductor. Semicond. Sci. Technol. 33(9), 095010 (2018)

23. T.-H. Tran-Thi, T.A. Mattioli, D. Chabach, A. De Cian, R. Weiss, Hole localization or delocalization? an optical, raman, and redox study of lanthanide porphyrin-phthalocyanine sandwich-type heterocomplexe. J. Phys. Chem. 98(34), 8279-8288 (1994)

24. R. Rousseau, R. Aroca, M.L. Rodriguezmendez, Extended huckel molecularorbital model for lanthanide bisphthalocyanine complexes. J. Mol. Struct. 356(1), 49-62 (1995)

25. D.K. Rittenberg, K. Sugiura, Y. Sakata, A.M. Arif, JS Miller Bis(phthalocyaninato)gadolinium(III)hexacyanobutadienide(1-), GdPc2 + [C4(CN)6]-an electron transfer salt with four paramagnetic site. Inorg. Chem. 40, 3654-3655 (2001)

26. B.J. Jones, S. Wright, R.C. Barklie, J. Tyas, J. Franks, A.J. Reynolds, Nanostructure and paramagnetic centres in diamond-like 
carbon: effect of Ar dilution in PECVD process. Diam. Relat. Mater. 17(7-10), 1629-1632 (2008)

27. C. Reese, M. Roberts, M.M. Ling, Z.N. Bao, Organic thin film transistors. Mater. Today 7(9), 20-27 (2004)

28. H.S. Kang, J.W. Lee, M.K. Kim, J. Joo, J.M. Ko, J.Y. Lee, Electrical characteristics of pentacene-based thin film transistor with conducting poly(3,4-ethylenedioxythiophene) electrodes. J. Appl. Phys. 100(6), 064508 (2006)

29. S. Locci, M. Morana, E. Orgiu, A. Bonfiglio, P. Lugli, Modeling of short-channel effects in organic thin-film transistors. IEEE Trans. Electron Devices. 55(10), 2561-2567 (2008)

30. A.R. Brown, C.P. Jarrett, D.M. de Leeuw, M. Matters, Fieldeffect transistors made from solution-processed organic semiconductors. Synth. Met. 88(1), 37-55 (1997)

31. L.A. Dobrun, A.P. Kovshik, E.I. Ryumtsev, Y.G. Galyametdinov, A.A. Knyazev, Dielectric properties of gadolinium-based liquid crystalline complex. Crystallogr. Rep. 62(5), 753-757 (2017)

32. M. Egginger, S. Bauer, R. Schwodiauer, H. Neugebauer, N.S. Saricififtci, Current versus gate voltage hysteresis in organic field effect transistors. Mon. Chem. 140, 735-750 (2009)

33. T. Faris, T. Basova, N.B. Chaure, A.K. Sharma, M. Durmus, V. Ahsen, A.K. Ray, Effects of annealing on device parameters of organic field effect transistors using liquid-crystalline tetrasubstituted zinc phthalocyanine. EPL. 106(5), 58002 (2014)

34. C.Y. Kagan, P.W.E. Andry, Thin Film Transistors (Dekker, New York, 2003), p. 87

35. L. Vijayan, A. Thomas, K.S. Kumar, K.B. Jinesh, Low power organic field effect transistors with copper phthalocyanine as active layer. J. Sci. Adv. Mater. Dev. 3(3), 348-352 (2018)

36. Q. Liu, Y. Li, X.Y. Wang, W. Huang, J. Ma, Y. Li, Y. Shi, X.Z. Wang, Z. Hu, Enhancing charge transport in copper phthalocyanine thin film by elevating pressure of deposition chamber. Org. Electron. 15(8), 1799-1804 (2014)

37. T. Rothlaender, A. Fian, J. Kraxner, W. Grogger, H. Gold, A. Haase, B. Stadlober, Channel length variation in self-aligned, nanoimprint lithography structured OTFTs. Org. Electron. 15(11), 3274-3281 (2014)

38. P.B. Shea, J. Kanicki, N. Ono, Field-effect mobility of polycrystalline tetrabenzoporphyrin thin-film transistors. J. Appl. Phys. 98(1), 014503 (2005)
39. D. Natali, L. Fumagalli, M. Sampietro, Modeling of organic thin film transistors: effect of contact resistances. J. Appl. Phys. 101(1), 014501 (2007)

40. Mathworks, MATLAB Curve Fitting Toolbox User's Guide, Mathworks, Inc 2018, USA (2018)

41. U.K. Mishra, J. Singh, Semiconductor Device Physics and Design, pp. 356-432. Springer, Berlin (2008)

42. J.B. Kuo, S.C. Lin, Low-Voltage SOI CMOS VLSI Device and Circuits (Wiley, New York, 2001), p. 23

43. J.H. Schon, B. Batlogg, Trapping in organic field-effect transistors. J. Appl. Phys. 89, 336-342 (2001)

44. M. Kim, I.K. You, H. Han, S.W. Jung, T.Y. Kim, B.K. Ju, J.B. Koo, Organic thin-film transistors with short channel length fabricated by reverse offset printing. Electrochem. Solid State Lett. 14(8), H333-H336 (2011)

45. D. Hertel, H. Bässler, U. Scherf, H.H. Hörhold, Charge carrier transport in conjugated polymers. J. Chem. Phys. 110(18), 92149222 (1999)

46. D.J. Gundlach, L. Zhou, J.A. Nichols, T.N. Jackson, P.V. Necliudov, M.S. Shur, An experimental study of contact effects in organic thin film transistors. J. Appl. Phys. 100(2), 024509 (2006)

47. B. Iniguez, R. Picos, D. Veksler, A. Koudymov, M.S. Shur, T. Ytterdal, W. Jackson, Universal compact model for long- and short-channel thin-film transistors. Solid-State Electron. 52, 400-405 (2008)

48. J. Levinson, F.R. Shepherd, P.R. Scanlon, W.D. Westwood, G. Este, M. Rider, Conductivity behaviour in polycrystalline semiconductor thin film transistors. J. Appl. Phys. 53(2), 1193-1202 (1982)

Publisher's Note Springer Nature remains neutral with regard to jurisdictional claims in published maps and institutional affiliations. 